\title{
Experience with the use of sugar paste dressing followed by reconstruction of sacral pressure sore with V-Y flap: A reliable solution for a major problem
}

\author{
Mohammad Ruhullah*, Shah Sanjay, HR Singh, KD Sinha, M. Irshad, B. Abhishek, S. Kaushal \\ and S. K. Shambhu
}

Department of Orthopaedic Surgery, National Medical College and Teaching Hospital, Birgunj, Nepal.

Accepted 7 February, 2013

\begin{abstract}
Pressure sore is a complication in paraplegic/quadriplegic patients. Despite advances in reconstruction techniques, sacral pressure sores are still a challenge to the orthopaedic surgeon, because of long hospital stay resulting into the situation where pressure sores are in evitable for ambulatory patients too. Development of pressure sores makes treatment/rehabilitation difficult and delays treatment options. Additionally, untreated sores cause complications, e.g. death and recurrence after surgery. Attention has been focused on aggressive dressing of the deep sores with use of sugar paste. Once granulation tissue had filled a sore cavity, a surgical closure using V-Y flaps were considered a method providing better treatment results. This study was conducted on 14 patients (10 males and 4 females) with sacral pressure sores in age group of 35 to 80 years. After initial debridement and removal of tissues of doubtful viability, culture and sensitivity were done in all cases. Wounds were packed with sugar paste for $\mathbf{5}$ to $\mathbf{1 4}$ days or till cavity is filled by granulation tissue. Bilateral V-Y myocutaneous flaps were used in 13 cases. Wound gaping occurred in 1 due to failure of a unilateral rotational flap and secondary bilateral V-Y myocutaneous flaps were needed. Suction drains retained for 7 to 10 days and pressure bearing on sores sites was avoided till complete healing. Superficial infection occurred in 3 cases which responded to suction and dressings. In our experience, the use of sugar paste dressing as a preprocedure to $V-Y$ flap covering operation is a reliable options in management of infected deep sacral pressure sore.
\end{abstract}

Key words: Sugar paste, V-Y flaps, sacral sore.

\section{INTRODUCTION}

Pressure sores, especially in the sacral region, are a common recurring complication in patients who are paraplegic, quadriplegic or bed bound. Many surgical methods have been used to correct pressure sores, including primary closure, skin grafting, local random flaps, and muscle flaps. Many musculocutaneous/myocutaneous and fasciocutaneous flaps are described to cover defects in this area (Phillips and Robson, 1990). Sacral pressure sores have popularly been closed using the gluteus maximus myocutaneous flap which has reliable vascularity (Stevenson et al., 1987).

In this study, daily sugar paste dressing for a period of 5 to 14 days was performed. The sugar paste dressing facilitated autolytic debridement of the infected deep pressure sore wound and promoted granulation tissue formation to fill the deep cavity of sore with a reduction in 
Med. Pract. Rev.

wound size (Seal and Middleton, 1991). A moist wound bed was maintained and bacterial colonisation was prevented. Once granulation tissue had filled a cavity of deep sacral sore, a surgical closure using V-Y myocutaneous flaps were considered which is a reliable technique used in covering defects and wounds.

\section{MATERIALS AND METHODS}

Between September, 2008 and December, 2010, 14 patients with deep sacral pressure sores were studied in the Department of Orthopaedics, National Medical College, Birgunj, Nepal. They were 10 males and 4 females with an age range 35 to 80 (mean 67.7) years. All the patients were bedridden because of paraplegia and quadriplegia. All defects were of grade III or IV pressure sores over the sacral region according to the classification in Shea (1975) study (Figure 1).

The clinical examination was done according to the guidelines of the International Standards for Neurological Examination and Functional Classification of Spinal Cord Injury (ASIA Grade) (Ditunno et al., 1985).

The data collected for pressure ulcer were number, site, duration and staging of each ulcer. Photographs of all ulcers were taken preoperatively, postoperatively, after suture removal and repeated at follow up. The intervention was divided into three continuous stages of preoperative, operative and post operative management. The preoperative management consisted of proper nursing care, bedside debridement, sugar paste dressing till formation of granulation tissue to fill the cavity and education to the patient or attendant regarding pressure sore care. Operative interventions were decided on the basis of ulcer stage, debridement, clean and formation of the granulation tissue.

Sacral pressure sore of all patients were initially bedside dressing with betadine and hydrogen peroxide; debrided and suspiciously viable tissue were removed. Culture and sensitivity samples were taken from all wounds. Finally, the wounds were washed with normal saline and packs with sugar paste twice daily for a period of 5 to 14 days till granulation tissue had filled a cavity of deep wound and intravenous antibiotics were started for one week, followed by oral to control the infection. Once granulation tissue had filled a cavity of wound, bilateral $V-Y$ myocutaneous flaps were performed under general anaesthesia in 14 cases. Grade IV antibiotics were introduced $1 \mathrm{~h}$ prior to flap surgery, and then continued for seven days. Patients were all put on air mattresses and weight bearing was not allowed on the back completely for a period of 2 to 3 weeks until complete healing of the wound edges.

\section{Sugar paste application techniques}

At bedside, the patient's leg and back were washed with lukewarm tap water and soap to minimize bacterial spread to the surrounding skin and to prevent migration into the wound. The sacral area was dried with sterile gauge. This allowed clean and easy visual assessment of the entire leg as well as sacral region. The sore was initially debrided, washed with gauge soaked in betadine solution with hydrogen peroxide, irrigated thoroughly with normal saline and suspiciously viable tissue removed. Soft paraffin was applied gently granulated sugar into the sugar paste. The sugar was secured in place with $13.5 \times 11.5 \mathrm{~cm}$ impregnated gauze dressing or a transparent film dressing and was sealed with plaster tape or masking tape to hold the sugar paste in place. Polythene films were also used to secure sugar in place. When everywhere was sealed, an air vent was formed by inserting a one finger between the tape and the patient's skin as the tape was applied, so that any ooze from inside may not cause any elevation of the part of the tape/polythene films from the sore surface. Dressings were changed twice daily for the first five days and then daily from the 6 to the 14th day. Middleton (1990) who stated that the dressing should be changed twice a day because the sugar paste liquefied and there will be leakage from the dressings if left for a longer time. Once granulation tissue had filled a cavity of deep sacral sore (Figure $2 a$ and b), sugar paste dressing should be stopped and plan for a surgical closure should be done using $\mathrm{V}-\mathrm{Y}$ myocutaneous flap, which is a reliable technique and most effective procedure (Figure 3 ).

\section{RESULTS}

No flaps were lost in all cases except one. At one week post operative in 1 case of unilateral rotational flap (Figure 4), wound gaping occurred due to cut through sutures from skin. It was noted that after surgical closure with unilateral fasciocutaneous rotation flap, the patient were operated on for the second time using bilateral V-Y myocutaneous flaps under general anesthesia with a good result on follow up (Figure 5 ). Suction drains were applied in all cases for a period of 7 to 10 days and non weight bearing was sustained for a period of at least two weeks or until complete healing occurred. Superficial infection occurred in 3 cases and they responded to repeated dressings with IV antibiotics.

\section{DISCUSSION}

Pressure sores, especially in the sacral region, are a common recurring complication in patients who are paraplegic, quadriplegic or bed bound with high morbidity and mortality rates. Pressure sores can be avoided only by meticulous care, careful attention to simple bladder drainage and proper rehabilitation measures. Many surgical methods have been used to correct pressure sores, including primary closure, skin grafting, local random flaps, and muscle flaps. Many musculocutaneous and fasciocutaneous flaps were described to cover defects in this area (Phillips and Robson, 1990). Sacral pressure sores have popularly been closed using the gluteus maximus myocutaneous flap which has reliable vascularity (Stevenson and Pollock, 1987).

But before the surgical closure of deep pressure sore by different method of flaps filling, the deep cavity of the sore with granulation tissue, liquefying devitalized dead tissue and eliminating wound malodour as well as keeping the wound surfaces moist were not reported in most literature. If the wound becomes dry, the cells necessary for vascularisation and tissue generation die. The formation of granulation tissue can only take place in a homogeneously moist wound environment. The wound floor must never be allowed to dry out and must be kept 


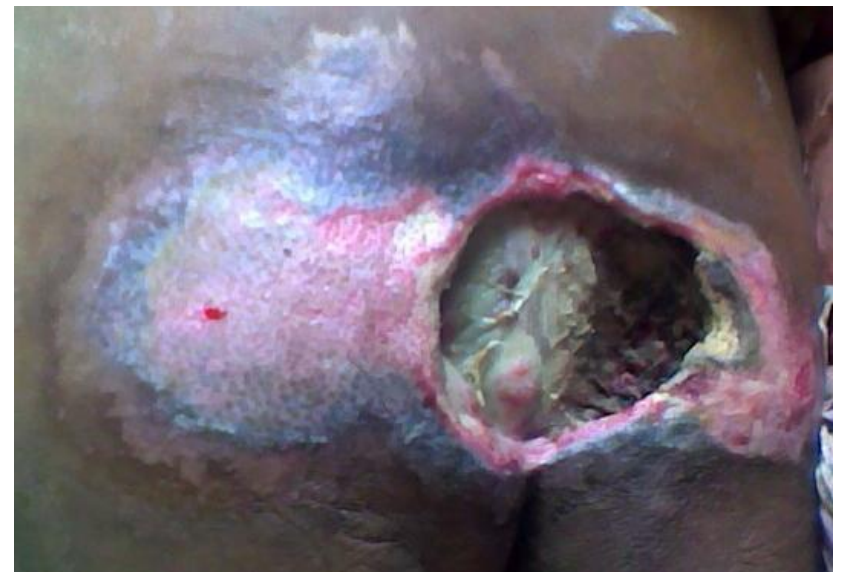

Figure 1. Pretreatment appearance of sacral pressure sore (size: $9.5 \times 6.5 \times 2.5 \mathrm{~cm}$ ).
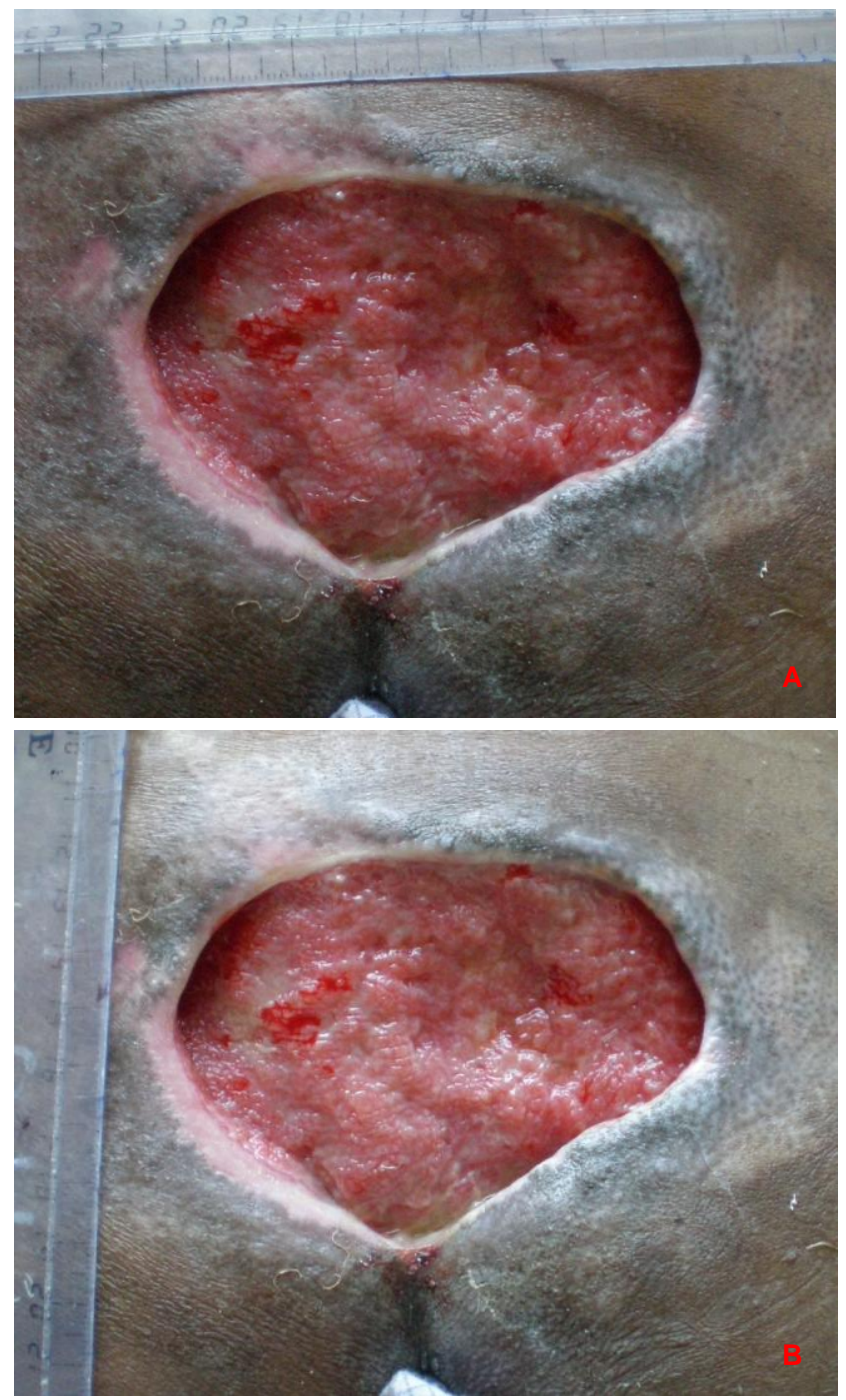

Figure 2. Appearance of pressure sores before $(A)$ and after (B) sugar paste dressing. 


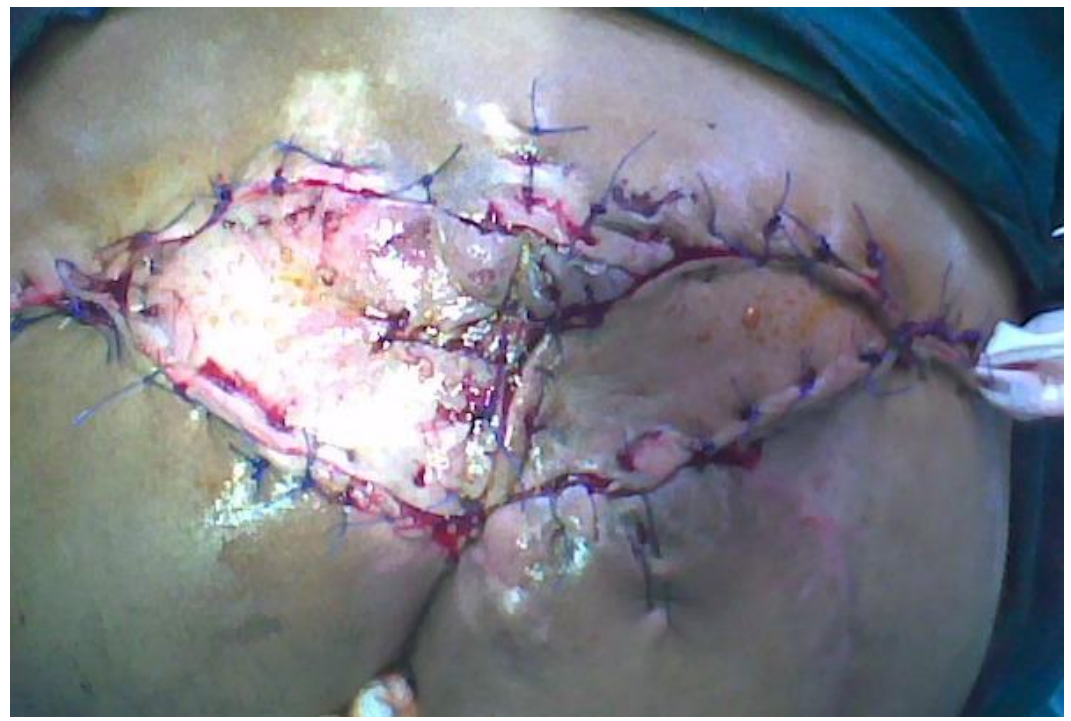

Figure 3. Closure by V-Y Flap.

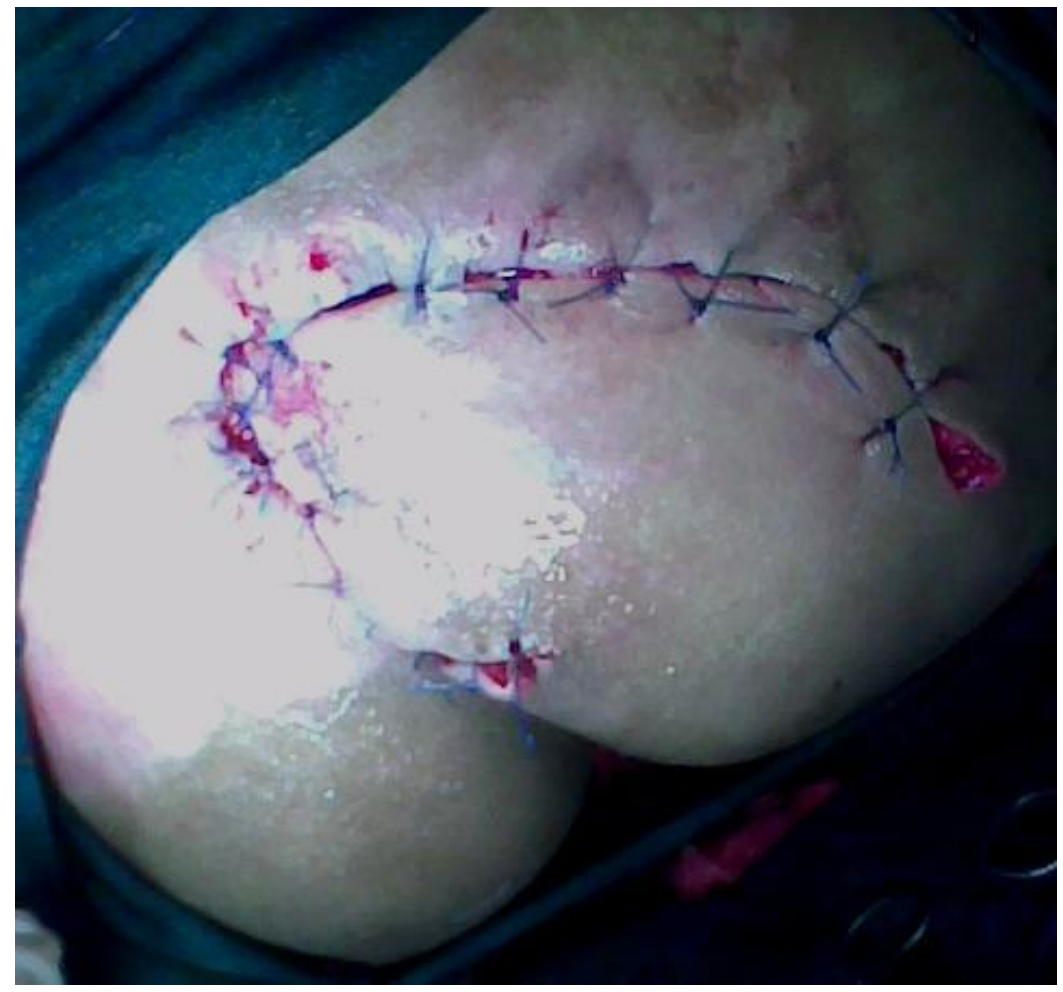

Figure 4. Closure by Rotational Flap.

permanently moist. Promoting and maintaining this moist wound environment is therefore the most important task of a sugar paste dressing method of filling the deep cavity of the sore. Once granulation tissue had filled a cavity, epithelium grew in from the edges at approximately $2 \mathrm{~mm}$ a day. This meant that a wound that is $10 \mathrm{~cm}$ in diameter would be completely covered in about three weeks.

In this study, daily sugar paste dressing was performed for a period of 5 to 14 days. This study demonstrates that sugar paste, is a relatively cheap dressing and it is readily 


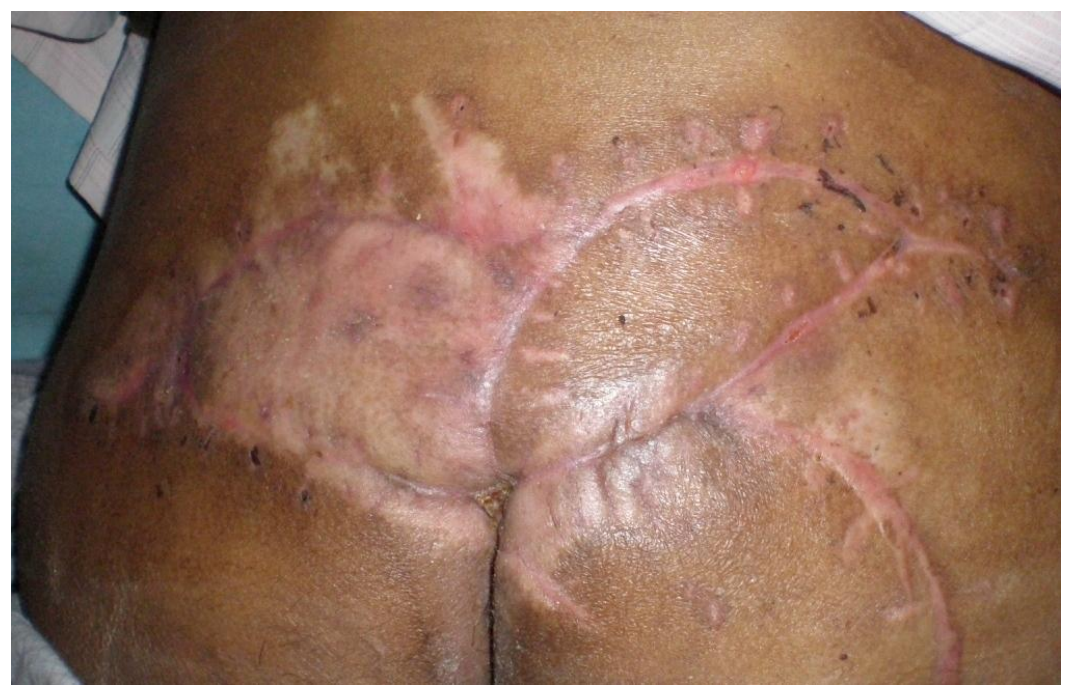

Figure 5. Appearance of pressure sore after sugar paste dressing and V-Y flap.

readily available. Once granulation tissue had filled a cavity of deep sacral sore, a surgical closure using $\mathrm{V}-\mathrm{Y}$ myocutaneous flaps were considered which is a reliable technique used in covering defects and wounds providing better results. Long term treatment results is based on the ability to distribute pressure to prevent a recurrence, it is not based on the type of flap used for cover. There is a high incidence of recurrence (Parry and Park, 1989; Mandrekas and Mastorakos, 1992; Relander and Palmer, 1988).

Granulated sugar and honey have been used to treat wounds, particularly in infected wounds for many years and still it is in traditional and cultural medicine (Seal and Middleton, 1991; Bhanaganada et al., 1987). Granulated sugar is the disaccharide sucrose and will combine with other substances such as water (Engelsen and Perez, 1997). When sugar is applied to a wound it will normally dissolve within $4 \mathrm{~h}$, creating a highly concentrated environment on the wound surface. Body fluids are attracted to the wound surface to equalise the high concentration gradient (osmosis), increasing the volume of exudate produced. This appears to cleanse/irrigate the wound and to liquefy devitalised dead tissue. The dead tissue is removed each time the wound is re-dressed, promoting the generation of new tissue.

The presence of hydrogen peroxide in the honey is thought to stimulate the formation of granulation tissue and re-epithelialisation of the wound (Dawson, 1996; Pieper and Caliri, 2003). Honey and sugar paste appear to exert their effects on wound healing due to their high osmolarity which prevents certain bacteria from growing.
The hypertonicity of sugar relieves periwound edema, allowing serum and nutrients to enter wound tissues. Sugar also lowers water activity level to one in which microorganisms cannot proliferate (Dawson, 1996; Pieper and Caliri, 2003). Both honey and sugar paste provide a moist wound environment and are non-adherent causing no trauma to the wound on removal. These promote healing by keeping the wound surfaces moist, thereby allowing the natural regenerative processes of the body to take place while inhibiting the growth of bacteria and fungi as a result of their low water activity, because the bacteria need water to live (Hinman and Maibach, 1963; Loncin and Merson, 1979). They also promote debridement of the wound and help to eliminate wound malodour.

When dry granulated sugar is poured into an open wound, any surface moisture is taken up by osmosis and this drying effect can lead to the formation of an intense burning sensation. Hence, sugar paste which do not exert this effect are now preferred to dry sugar for wound treatment in Western Medicine (Middleton, 1990; Knutson et al., 1981).

Some hospital dressers mix sugar with hydrogen peroxide to form a kind of paste and then put that paste directly to open sores, especially on bedsores. Sugar is widely used in a number of countries across Africa and there has been more limited use in the UK and the US. The largest study in the US ran over a 56-month period and treated a total of 605 patients with wounds of different aetiologies. The study reported rapid wound healing when using sugar and povidone-iodine to enhance 
wound healing (Knutson et al., 1981). In the UK, one small case study found that packing malodorous pressure ulcers with sugar paste stopped the odour and debrided necrotic tissue (Seal and Middleto, 1991). More recently, Mphande et al. (2007) compared the effects of sugar and honey on wound healing and observed no significant difference between the two.

Many musculocutaneous and fasciocutaneous flaps are described to cover defects in this area (Phillips and Robson, 1990; Dawson, 1996; Pieper and Caliri, 2003; Parry and Park, 1989; Khatri et al., 1994; Mandrekas and Mastorakos, 1992; Relander and Palmer, 1988; Evans et al., 1994). In this study, an attempt will be done to achieve the best possible coverage with the least compromise to the patient general health and well being.

In $\mathrm{V}$ - $\mathrm{Y}$ plasty technique, an incision is made as $\mathrm{V}$ pattern and approached to cover the defected area as $Y$ shape. Most authors offered the technique as a reliable method for reconstruction of wound defects (Dawson, 1996; Pieper and Caliri, 2003; Parry and Park, 1989; Khatri et al., 1994; Mandrekas and Mastorakos, 1992; Relander and Palmer, 1988; Evans et al., 1994). The covering of the defects in sacral pressure sores must be reliable and let the wound heal without complication. In this study, V-Y flaps usage in weight bearing areas was emphasized.

\section{Conclusion}

This study demonstrates that sugar paste, which is a relatively cheap dressing, can be effective on infected, malodorous wounds of different aetiology, including pressure ulcers. In our experience, once granulation tissue had filled a cavity of deep sacral sore, a surgical closure using V-Y myocutaneous flaps were considered which is a reliable technique used in covering defects and wounds providing better long term treatment results.

\section{REFERENCES}

Bhanaganada K, Kiettiphongthavorn V, Wilde H (1986). The use of super-saturated sucrose solution for chronic skin ulcers (Resurrection of an old remedy). J. Med. Assoc. Thai. 69(7):358-365.

Dawson JS (1996). Preiskel Elective Prize. The role of sugar in wound healing. A comparative trial of the healing of infected wounds using traditional guaze/antiseptic packing and granulation sugar, undertaken during an elective period at Kagando Hospital, Uganda. Ann. R. Coll. Surg. Engl. 78(2 Suppl):82-85.
Ditunno JF, Young W, Donovan WH, Creasey G (1994). The International Standard Booklet for neurological and functional classification of spinal cord injury. American Spinal Injury Association. Paraplegia 32(2):70-80.

Engelsen SB, Perez S (1997). Internal motions and hydration of sucrose in diluted water solution. J. Mol. Graph. Model 15(2):122131.

Evans GR, Dufresne CR, Manson PN (1994). Surgical correction of pressure ulcers in an urban center; is it efficacious? Adv. Wound Care 7(1):40-46.

Hinman CD, Maibach H (1963). Effect of air exposure and occlusion on experimental human skin wounds. Nature 200:377-378.

Khatri VP, Espinosa MH, Amin AK (1994). Management of recurrent pilonidal sinus by simple V-Y fasciocutaneous flap. Dis. Colon Rectum 37:1232-1235.

Knutson RA, Merbitz LA, Creekmore AA, Snipes HG (1981). Use of sugar and povidone iodine to enhance wound healing. Five years experience. South Med. J. 74(11):1329-335.

Loncin MC, Merson RL (1979). Food engineering: Principles and selected applications. Academic Press, London. pp. 195-202.

Mandrekas AD, Mastorakos DP (1992). The management of Decubitus ulcers by musculocutaneous flaps: A five year experience. Ann. Plast. Surg. 28(2):167-174.

Middleton K (1990). Sugar pastes in wound management. Dressings Times Newslett. 3(2).

Mphande AN, Kilowe C, Phalira S, Jones HW, Harrison WJ (2007). Effects of honey and sugar dressings on wound healing. J. Wound Care 16(7):317-319.

Parry S, Park RC (1989). Fasciocutaneous V-Y advancement flap for repair of sacral defects. Ann. Plast. Surg. 22:543-546.

Phillips LG, Robson MC (1990). Pathobiology and treatment of pressure ulcerations. In: Jurkiewicz MJ (ed.), Plastic Surgery, Principles and Practice. St. Louis, Mosby. pp. 1223-1251.

Pieper B, Caliri MH (2003). Nontraditional wound care: A review of the evidence for the use of sugar, papaya/papain,and fatty acids. J. Wound Ostomy Continence Nurs. 30(4):175-183.

Relander M, Palmer B (1988). Recurrence of surgically treated pressure sores. Scand. J. Plast. Reconstr. Hand Surg. 22(1):89-92.

Seal DV, Middleton K (1991). Healing of cavity wounds with sugar. Lancet 338(8766):571-572.

Shea JD (1975). Pressure sores: Classification and management. Clin. Orthop. Telat. Res. 112:89-100.

Stevenson TR, Pollock RA, Rohrich RJ, Vanderkolk CA (1987). The gluteus maximus musculocutaneous island flap: Refinements in design and application. Plast. Reconstr. Surg. 79(5):761-768. 